No. 12(19)

\title{
DEGRESSIVELY PROPORTIONAL APPORTIONMENT OF SEATS IN THE EUROPEAN PARLIAMENT. FROM A SIMPLE IDEA TO A PROBLEMATIC LEGAL RULE
}

\author{
Katarzyna Cegiełka
}

\begin{abstract}
The proportional representation of citizens in collegial bodies is today the most frequently applied solution among electoral systems. It assumes an ideal condition with one delegate representing the same number of inhabitants, perceived as the fairest solution. However, in the European Parliament, fairness is seen somewhat differently. Due to the considerable dissimilarity of member states as regards the numbers of their populations, it is assumed as fair that delegates from less populous countries represent more citizens that those from more populous countries. Yet this seemingly uncomplicated idea, soon referred to as degressive proportionality, turned out to be a major problem in practice. This paper presents the story of the efforts to formalize degressive proportionality by members of the European Parliament.
\end{abstract}

Keywords: degressive proportionality, allocation of seats, European Parliament.

JEL Classification: D39.

DOI: $10.15611 / \mathrm{me} .2016 .12 .02$.

\section{Introduction}

The European Parliament as one of the institutions in the European Union has its origins at the beginning of the Union. The treaty establishing the European Coal and Steel Community was signed on 18 April 1951 in Paris, with four institutions, including a Common Assembly composed of national parliamentarians. The successive treaties, among others the Treaty of Rome in 1957 and the 1967 Merger (Brussels) Treaty, extended the role of the Assembly and provided it with more functions and powers. The 1986 Single European Act officially introduced the name "European Parliament" which has been used since 1962 and continues to be a legitimate term to this day [Cegiełka et al. 2010a].

\footnotetext{
Katarzyna Cegiełka

Department of Mathematics and Cybernetics, Wrocław University of Economics

katarzyna.cegielka@ue.wroc.pl
} 
Before 1979, the parliaments of the member states elected the members of the European Parliament. They have been directly elected in every member state according to their individual voting systems since 1979. The number of members of the European Parliament increased from 78 in its first term in 1952 to 751 in its eighth term that started in 2014 [Cegiełka et al. 2010b].

The composition of the Parliament has been inevitably subject to changes required by successive enlargements of the Union and by the demographic changes in member states. However, since the first term it has always been typical that delegates from more populous states represented more citizens than those from less populated states. For example, a member of the European Parliament from Germany in 1970 represented more than 760 thousand German citizens, whereas a member from Luxembourg represented around 60 thousand Luxembourgers. The mandates were not allocated proportionally, as in nearly all of the other electoral systems. Such a solution results from the considerable dissimilarity of populations in the member states of the European Union. In 1979 the number of citizens in the most heavily populated state, Germany, was 170 times greater than the number of the least populous Luxembourg [Cegiełka 2010]. In order to ensure a suitable representation while limiting the size of the Parliament, the application of methods other than proportional was required.

\section{Legal regulation of EP seats allocation. Origins of the degressive proportionality rule}

The increasingly fast development of the European Union and its successive enlargements required legal regulations with respect to methods of allocating seats to member states. The Treaty of Lisbon signed in 2007 and finally ratified in 2009 stipulated these regulations. The key clause regarding the apportionment of seats is articulated in point 15 of article 1: "The European Parliament shall be composed of representatives of the Union's citizens. They shall not exceed seven hundred and fifty in number, plus the President. Representation of citizens shall be degressively proportional, with a minimum threshold of six members per Member State. No Member State shall be allocated more than ninety-six seats" [Treaty of Lisbon 2007].

The Treaty labeled the form of citizens' representation as degressively proportional for the first time. However, no precise formal definition was provided. Article 1 of the Treaty merely introduced a new notion. A more detailed description of degressive proportionality was drafted in the annex to the Report 
of the Committee on Constitutional Affairs and the European Parliament Resolution by its rapporteurs, A. Lamassoure and A. Severin, who presented six principles underlying a precise definition of the rule of degressive proportionality [Lamassoure, Severin 2007]:

Principle 1. Efficiency - the EP could not function with more than a certain number of members, therefore the limitation of its maximum size to 751 is rational.

Principle 2. National representation and motivation of voters - each member state should have a minimum number of seats in order to have their national political main streams represented in the European Parliament, thus stimulating the national citizens to participate in voting and in the democratic process of the European Union.

Principle 3. European solidarity - the more populated states get less seats than they could be allocated by the application of full proportionality, in order to allow the less populated states to get a better representation than that to which they would be entitled otherwise.

Principle 4. Relative proportionality - the ratio of population to number of seats is smaller the smaller the state is, and respectively bigger the bigger the state is.

Principle 5. Fair distribution - no state will be allocated more seats than a bigger state or less seats than a smaller state.

Principle 6. Justified flexibility or flexible direct proportionality while observing the other principles, slight modifications of the number of seats could be introduced if they reduce as much as possible the differences between member states in terms of population and in terms of seats.

The above mentioned principles can be formalized as follows. Let $p_{i}$ denote the population of the $i$ th state and $s_{i}$ - the number of its seats, $i=1,2, \ldots, n$. Then:

Principle 1.

Principle 2.

$$
\sum_{i=1}^{n} s_{i} \leq 751
$$

Principle 4.

$$
s_{i} \geq 6
$$

Principle 5.

$$
p_{i}<p_{j} \rightarrow \frac{p_{i}}{s_{i}}<\frac{p_{j}}{s_{j}}
$$

$$
p_{i}<p_{j} \rightarrow s_{i} \leq s_{j}
$$


Table 1. Allocation of seats in EP in 2009-2014

Composition of European Parliament 2009-2014

\begin{tabular}{|c|c|}
\hline & Proposed (LT) composition \\
\hline
\end{tabular}

\begin{tabular}{|l|c|c|c|l|c|c|c|}
\hline \multicolumn{1}{|c|}{ Country } & $p_{i}$ & $s_{i}$ & $p_{i} / s_{i}$ & Country & $p_{i}$ & $s_{i}$ & $p_{i} / s_{1}$ \\
\hline Malta & 405006 & 5 & 81001 & Malta & 405006 & 6 & 6750 \\
\hline Luxembourg & 469086 & 6 & 78181 & Luxembourg & 469086 & 6 & 7818 \\
\hline
\end{tabular}

\begin{tabular}{|l|r|r|l|l|r|r|r|}
\hline Cyprus & 766414 & 6 & 127736 & Cyprus & 766414 & 6 & 127736 \\
\hline Estonia & 1344684 & 6 & 224114 & Estonia & 1344684 & 6 & 224114 \\
\hline Slovenia & 2003358 & 7 & 286194 & Slovenia & 2003358 & 8 & 250420 \\
\hline
\end{tabular}

\begin{tabular}{|l|r|r|l|l|l|r|r|r|}
\hline Slovenia & 2003358 & 7 & 286194 & Slovenia & 2003358 & 8 & 250420 \\
\hline Latvia & 2294590 & 8 & 286824 & Latvia & 2294590 & 9 & 254954 \\
\hline Lithuania & 3403284 & 12 & 283607 & Lithuania & 3403284 & 12 & 283607 \\
\hline
\end{tabular}

\begin{tabular}{|l|c|c|c|l|l|l|l|}
\hline Ireland & 4209019 & 12 & 350752 & Ireland & 4209019 & 12 & 350752 \\
\hline Finland & 5255580 & 13 & 404275 & Finland & 5255580 & 13 & 404275 \\
\hline Slovakia & 5389180 & 13 & 414552 & Slovakia & 5389180 & 13 & 414552 \\
\hline
\end{tabular}

\begin{tabular}{|l|r|r|r|l|r|r|r|}
\hline Slovakia & 5389180 & 13 & 414552 & Slovakia & 5389180 & 13 & 414552 \\
\hline Denmark & 5427459 & 13 & 417497 & Denmark & 5427459 & 13 & 417497 \\
\hline Bulgaria & 7718750 & 17 & 454044 & Bulgaria & 7718750 & 18 & 428819 \\
\hline Austria & 8265925 & 17 & 486231 & Austria & 8265925 & 19 & 435049 \\
\hline Sweden & 9047752 & 18 & 502653 & Sweden & 9047752 & 20 & 452388 \\
\hline Hungary & 10076581 & 22 & 458026 & Hungary & 10076581 & 22 & 458026 \\
\hline Czech Rep. & 10251079 & 22 & 465958 & Czech Rep. & 10251079 & 22 & 465958 \\
\hline Belgium & 10511382 & 22 & 477790 & Belgium & 10511382 & 22 & 477790 \\
\hline Portugal & 10569592 & 22 & 480436 & Portugal & 10569592 & 22 & 480436 \\
\hline Greece & 11125179 & 22 & 505690 & Greece & 11125179 & 22 & 505690 \\
\hline Netherlands & 16334210 & 25 & 653368 & Netherlands & 16334210 & 26 & 628239 \\
\hline Romania & 21610213 & 33 & 654855 & Romania & 21610213 & 33 & 654855 \\
\hline Poland & 38157055 & 50 & 763141 & Poland & 38157055 & 51 & 748178 \\
\hline Spain & 43758250 & 50 & 875165 & Spain & 43758250 & 54 & 810338 \\
\hline Italy & 58751711 & 72 & 815996 & Italy & 58751711 & 72 & 815996 \\
\hline Great Britain & 60393100 & 72 & 838793 & Great Britain & 60393100 & 73 & 827303 \\
\hline France & 62998773 & 72 & 874983 & France & 62998773 & 74 & 851335 \\
\hline Germany & 82437995 & 99 & 832707 & Germany & 82437995 & 96 & 858729 \\
\hline TOTAL & 492975207 & 736 & - & TOTAL & 492975207 & 750 & - \\
\hline
\end{tabular}

Source: [Cegiełka 2010]. 
The Report of the Committee on Constitutional Affairs explained the degressively proportional allocation of seats in the European Parliament and also put forward the composition of the Parliament in its seventh term (2009-2014). The composition satisfied the rule of degressive proportionality, i.e. it complied with all six principles, but the Treaty was ratified too late and entered into force in December of 2009, after the European Parliament election, therefore the proposed composition was not applied. The composition of the Parliament was based on the apportionment provided by the Treaty of $\mathrm{Nice}^{2}$, which was not degressively proportional. Both allocations are presented in Table 1.

\section{Mathematical description of degressive proportionality}

The principles emphasized by the Resolution and the provisions of the Lisbon Treaty motivated intense research into degressively proportional allocation, which can be defined as follows.

Definition 1. A positive sequence of shares $s=\left(s_{1}, s_{2}, \ldots, s_{n}\right)$ is degressively proportional with respect to positive, nondecreasing sequence of values (demands, claims) $p=\left(p_{1}, p_{2}, \ldots, p_{n}\right)$ is $s_{1} \leq s_{2} \leq \cdots \leq s_{n}$ and $p_{1} / s_{1} \leq$ $p_{2} / s_{2} \leq \cdots \leq p_{n} / s_{n}$.

As regards the European Parliament, the conditions included in Definition 1 embrace Principle 4 and Principle 5 from the 2007 Resolution, denoting the population of the ith state, and $s_{i}$ - the number of its seats. The other stipulations determined by the legal acts with respect to limits of the minimum (6), maximum (96), and total (751) number of seats in the European Parliament are called boundary conditions. In the above notation, the following hold:

$$
s_{1} \geq 6, \quad s_{n} \leq 96, \quad \sum_{i=1}^{n} s_{i} \leq 751 .
$$

As a matter of fact, the definition of degressive proportionality and boundary conditions do not specify the method of allocation; they only allow to test whether a given solution is degressively proportional. Therefore, given a sequence $p$, a set of degressively proportional allocations can be either empty or extremely huge ${ }^{3}$. As a result, many various methods of such allocations have

\footnotetext{
2 Interestingly enough, non-compliance with the rule of degressive proportionality occurred first in the final year of the fifth term of the European Parliament (1999-2004) when the largest single enlargement in terms of people and number of countries took place. Each previous composition of the Parliament satisfied then the unwritten rule [Cegiełka 2010].

${ }^{3}$ For example, with 2012 data the number of degressively proportional allocations exceeds 5 million [Łyko, Rudek 2013].
} 
been put forward (see for example [Łyko, Rudek 2013; Martinez-Aroza, Ramirez-Gonzalez 2008; Ramirez-Gonzalez 2007; Słomczyński, Życzkowski 2012; Serafini 2011]). The vast majority of them is based on a construction of a suitable real function which generates allocations. In addition, the method of rounding the values of this function is determined depending on a parameter or on some parameters so as to satisfy the boundary conditions $s_{1} \geq 6, s_{n} \leq 96, \sum_{i=1}^{n} s_{i} \leq 751$ (in practice, most of proposals assume equalities in all constraints instead of inequalities). At present such functions are called allocation functions ${ }^{4}$ which are defined as follows [Słomczyński, Życzkowski 2012].

Definition 2. Let $0<p_{1}<p_{n}, 0<m<M, p_{1} M<p_{n} m$. A function $A:\left[p_{1}, p_{n}\right] \rightarrow[m, M]$ is called a degressive allocation function if:

(1) $A$ is non-decreasing (monotonicity),

(2) $A$ is degressively proportional, i.e. the function $t \rightarrow A(t) / t$ is nonincreasing (degressive proportionality).

Notice that, due to the needed rounding of the values returned by the allocation function (typically non-integer), allocations generated in this way do not necessarily satisfy the degressive proportionality conditions specified by the 2007 Resolution. This means that even if the sequence $\left(A\left(p_{1}\right), A\left(p_{2}\right), \ldots, A\left(p_{n}\right)\right)$ is degressively proportional with respect to the sequence $p$, then if $s_{i}=\left[A\left(p_{i}\right)\right]$, where [-] denotes a selected rounding method, the sequence $\left(s_{1}, s_{2}, \ldots, s_{n}\right)=\left(\left[A\left(p_{1}\right)\right],\left[A\left(p_{2}\right)\right], \ldots,\left[A\left(p_{n}\right)\right]\right)$ does not have to be degressively proportional.

\section{Mathematicians coming to the rescue}

The efforts aimed at practically determining the degressive proportionality were made by the rapporteurs of the 2007 Report and summarized by the statement: "[an] ideal alternative would be to agree on an undisputed mathematical formula of 'degressive proportionality' that would ensure a solution not only for the present revision but for future enlargements or modifications due to demographic changes" [Lamassoure, Severin 2007]. An attempt to come up with a suitable solution was made in February 2011. A group of mathematicians headed by Professor Geoffrey Grimmett, who was asked by members of

\footnotetext{
${ }^{4}$ A detailed presentation of some selected classes of allocation can be found inter alia in [Słomczyński, Życzkowski 2012].
} 
the European Parliament to develop a method of allocating the EP seats, presented an algorithm of European apportionment to the Committee on Constitutional Affairs [Cegiełka 2012]. The scientists recommended two proposals:

- a new interpretation of the principle of degressive proportionality,

- an apportionment algorithm called the "Cambridge Compromise" adopting a "base+prop" method.

\section{A new interpretation of the principle of degressive proportionality}

Mathematicians argued that the legal interpretation specified in [Lamassoure, Severin 2007] as: "the principle of degressive proportionality means that the ratio between the population and the number of seats of each Member State must vary in relation to their respective populations in such a way that each Member from a more populous Member State represents more citizens than each Member from a less populous Member State and conversely, but also that no less populous Member State has more seats than a more populous Member State" should be replaced by: "the principle of degressive proportionality means that the ratio between the population and the number of seats of each Member State before rounding to whole numbers must vary in relation to their respective populations in such a way that each Member from a more populous Member State represents more citizens than each Member from a less populous Member State and conversely, but also that no less populous Member State has more seats than a more populous Member State" [Grimmett 2012].

Why did mathematicians recommend the revision of the interpretation by A. Lamassoure and A. Severin? They argued that such a case is possible when no degressively proportional allocation exists. It seems, however, that they additionally assumed that every method of apportionment will use some allocation functions and typical rounding methods such as upwards rounding, downwards rounding, and rounding to the nearest integer. Hence, a degressively proportional allocation should be interpreted as follows.

Definition 3. Let $p=\left(p_{1}, p_{2}, \ldots, p_{n}\right)$ denote a positive, non-decreasing sequence of values (demands, claims), $A:\left[p_{1}, p_{n}\right] \rightarrow \mathbb{R}_{+}$denote a function, and ['] denote a rounding rule. A sequence of shares $\left(s_{1}, s_{2}, \ldots, s_{n}\right)=$ $\left(\left[A\left(p_{1}\right)\right],\left[A\left(p_{2}\right)\right], \ldots,\left[A\left(p_{n}\right)\right]\right)$ is degressively proportional with respect to sequence $p$ if $s_{1} \leq s_{2} \leq \cdots \leq s_{n}$ and $p_{1} / A\left(p_{1}\right) \leq p_{2} / A\left(p_{2}\right) \leq \cdots \leq$ $p_{n} / A\left(p_{n}\right)$. 
As a result of such understanding of degressive proportionality, the rule becomes weaker in the following sense. Each allocation $\left(s_{1}, s_{2}, \ldots, s_{n}\right)$ such that $s_{1} \leq s_{2} \leq \cdots \leq s_{n}$, generated by an allocation function, is degressively proportional. On one hand, this feature makes the search for desired allocations much easier. On the other hand though, this opens the door to considerable abuse. Consider the allocation function $A(t)=751 / n$, where $n$ denotes the number of member states ${ }^{5}$.This function returns an equal apportionment, i.e. allocates an equal number of seats to each state (before rounding). One can easily define a rounding rule that will return sequence $\left(s_{1}, s_{2}, \ldots, s_{n}\right)$ which satisfies $s_{1} \leq s_{2} \leq \cdots \leq s_{n}$ and $s_{1}=6, s_{n}=96, \sum_{i=1}^{n} s_{i}=751$, but ratios $p_{i} / s_{i}$ will be far from satisfying the desired inequalities $p_{1} / s_{1} \leq$ $p_{2} / s_{2} \leq \cdots \leq p_{n} / s_{n}$. Such a solution will be far from the initial idea presuming that more populated states represent greater numbers of citizens than less populated states. However, in spite of potential threats, parliamentarians agreed to the proposed modification of understanding degressive proportionality, officially adopted by the European Parliament in its 2013 Resolution.

\section{Cambridge Compromise}

The "base+prop" method with an equally called allocation function consists in allocating a certain common number of (base) seats to each state and in distributing the remaining number of seats proportionally (prop) and subject to a maximum number of seats. Mathematicians determined that the best base equals five seats, and the best proportional scheme is the divisor method with upwards rounding ${ }^{6}$. In this way every state is assigned six seats as guaranteed by the Lisbon Treaty.

Mathematicians proposed this method as a simple, transparent and durable formula expected by parliamentarians. In addition, with a modified interpretation, this method returns a degressively proportional allocation. The members of parliament confirmed that the proposed method ensures the allocation of seats with the desired property of degressive proportionality, but

5 If we demand that the values of allocation function for the smallest state and the largest state were equal to 6 and 96, respectively, we can take, for example, a linear function passing through the points $\left(p_{1}, 6\right),\left(p_{n}, 96\right)$.

${ }^{6}$ Divisor methods consist in finding a constant $d$ such that $\sum_{i=1}^{n}\left[p_{i} / d\right]=H$, where $p_{i}$ denotes the population of the ith state, $\mathrm{H}$ denotes a total number of allocated seats, and [·] denotes a selected rounding method (e.g. standard rounding to the nearest integer). A detailed description of the classical methods of proportional apportionment can be found inter alia, in [Young 1994; Pukelsheim 2014]. 
they claimed that "its implementation would trigger a traumatic reallocation of seats, with heavy losses for medium-sized and small Member States and huge increases for larger ones" [Gualtieri, Trzaskowski 2013]. As a result, the algorithm was not accepted.

\section{The allocation of seats in the European Parliament in the 2014-2019 term}

Parliamentarians rejected the Cambridge Compromise, but they had to determine the composition of the Parliament for its term (2014-2019). This was necessary because Croatia accessed the Union, and due to compliance with the Lisbon Treaty which entered into force in 2010. The differences between the composition adopted in the 2007 Resolution and the Treaty caused the under-representation of some states. In 2010 the size of the European Parliament was increased by 18 seats. Croatia accessed the European Union in July 2013, with 12 observers assigned in April 2012. At the time when the composition of the Parliament for the eighth term was to be determined, its size was 766 members. In compliance with the provisions of the Lisbon Treaty, the size cannot exceed 751, therefore the number of parliamentarians had to be decreased by 15 . Therefore the rapporteurs of the Committee, $\mathrm{R}$. Gualtieri and R. Trzaskowski, proposed the principle "nobody gains and nobody loses more than one" [Gualtieri, Trzaskowski 2013].

They proposed the allocation based on this principle, which was not degressively proportional, as they admitted, but the loss of seats vs. previous composition was minimized. In so doing, they again rejected the Cambridge Compromise, which - in view of the rapporteurs - led to solutions deviating too far from the composition in the seventh term. Instead, they proposed a pragmatic solution based on a two-step approach. The first step was the reallocation of seats involving minimal changes in the number of seats, fully compliant with the principle of degressive proportionality. The second step was the political compensation between the gains and the losses determined in step 1, when states losing some of their seats were selected [Gualtieri, Trzaskowski 2013]. The solution provided by R. Gualtieri and R. Trzaskowski is presented in Table 2. Finally, the Parliament adopted the composition very close to the pragmatic approach. The only differences are the numbers of seats allocated to Austria (18) and to Sweden (20). 
Table 2. Allocation of seats in the EP due to the pragmatic solution in 2014-2019

\begin{tabular}{|l|r|r|r|l|r|r|c|}
\hline \multirow{2}{*}{ Country } & \multirow{2}{*}{$p_{i}$} & $2009-2014$ & \multicolumn{2}{|c|}{ Step 1 } & \multicolumn{3}{c|}{ Step 2 } \\
\cline { 3 - 8 } & & $s_{i}$ & \multicolumn{1}{|c|}{$s_{i}$} & Difference & $s_{i}$ & Difference & $p_{i} / s_{i}$ \\
\hline Malta & 416110 & 6 & 6 & & 6 & & 69352 \\
\hline Luxembourg & 524853 & 6 & 6 & & 6 & & 87476 \\
\hline Cyprus & 862011 & 6 & 6 & & 6 & & 143669 \\
\hline Estonia & 1339662 & 6 & 6 & & 6 & & 223277 \\
\hline Latvia & 2041763 & 9 & 7 & minus 2 & 8 & minus 1 & 255220 \\
\hline Slovenia & 2055496 & 8 & 7 & minus 1 & 8 & & 256937 \\
\hline Lithuania & 3007758 & 12 & 9 & minus 3 & 11 & minus 1 & 273433 \\
\hline Croatia & 4398150 & 12 & 11 & minus 1 & 11 & minus 1 & 399832 \\
\hline Ireland & 4582769 & 12 & 11 & minus 1 & 11 & minus 1 & 416615 \\
\hline Finland & 5401267 & 13 & 13 & & 13 & & 415482 \\
\hline Slovakia & 5404322 & 13 & 13 & & 13 & & 415717 \\
\hline Denmark & 5580516 & 13 & 13 & & 13 & & 429270 \\
\hline Bulgaria & 7327224 & 18 & 17 & minus 1 & 17 & minus 1 & 431013 \\
\hline Austria & 8443018 & 19 & 19 & & 19 & & 444369 \\
\hline Sweden & 9482855 & 20 & 19 & minus 1 & 19 & minus 1 & 499098 \\
\hline Hungary & 9957731 & 22 & 19 & minus 3 & 21 & minus 1 & 474178 \\
\hline Czech Rep. & 10505445 & 22 & 20 & minus 2 & 21 & minus 1 & 500259 \\
\hline Portugal & 10541840 & 22 & 20 & minus 2 & 21 & minus 1 & 501992 \\
\hline Belgium & 11041266 & 22 & 20 & minus 2 & 21 & minus 1 & 525775 \\
\hline Greece & 11290935 & 22 & 20 & minus 2 & 21 & minus 1 & 537664 \\
\hline Netherlands & 16730348 & 26 & 26 & & 26 & & 643475 \\
\hline Romania & 21355849 & 33 & 31 & minus 2 & 32 & minus 1 & 667370 \\
\hline Poland & 38538447 & 51 & 51 & & 51 & & 755656 \\
\hline Spain & 46196276 & 54 & 57 & plus 3 & 54 & & 855487 \\
\hline Italy & 60820764 & 73 & 74 & plus 1 & 73 & & 833161 \\
\hline Great Britain & 62989550 & 73 & 76 & plus 3 & 73 & & 862871 \\
\hline France & 65397912 & 74 & 78 & plus 4 & 74 & & 883756 \\
\hline Germany & 81843743 & 99 & 96 & minus 3 & 96 & minus 3 & 852539 \\
\hline TOTAL & 508077880 & 766 & 751 & & 751 & & \\
\hline & & & & & & & \\
\hline
\end{tabular}

Source: [Gualtieri, Trzaskowski 2013]. 


\section{More searching for undisputable mathematical formula. The 2019-2024 term}

Further activities aimed at developing a universal method to determine the composition of the European Parliament were launched before the ninth parliamentary term (2019-2024). In January 2017 the Committee on Constitutional Affairs (AFCO) invited again the group of mathematicians (mostly the same persons as before). The scientists discussed various methods. This time they were not quite in agreement on the subject as before. Summarizing their discussion one can indicate the three main proposals:

- the Power Compromise algorithm of allocating seats based on the "base+power" method,

- the 0.5-DPL method,

- the modification of the existing voting system in the Council of the European Union (the Jagiellonian Compromise).

\section{Power Compromise}

The proposed method based on the "base+power" allocation function to determine the composition of the European Parliament is a variant of the Cambridge Compromise. The procedure is following: "Every Member State is assigned a common number of base seats. The remaining seats are allocated proportionally to adjusted population units (that is, the population figures raised to a common power) using the divisor method with upward rounding. In the case of the current EP, the number of base seats, the power, and the divisor are determined so that the least populous Member State is allocated 6 seats, the most populous is allocated just 96 seats, and the size of the EP is 751." [Grimmett et. al. 2017]. Given the current composition of the European Parliament, the best base is five seats, the common power equals 0.93 , with the upward rounding of function values.

In order to justify their proposal, the mathematicians point out two main arguments. First, considering the standpoint of parliamentarians who reluctantly agree to the solutions that significantly change the status quo (as was the case of the Cambridge Compromise), the mathematicians argue that among the various allocation functions, the "base+power" method minimizes the number of seats transferred. Second, the "base+power" scheme is characterized by the so-called super-proportionality, which results in more degressive proportionality, in a sense, than in the case of allocation functions that are not super-proportional, for details see [Grimmett et al. 2017]. 


\section{5-DPL method}

This method belongs to the family of r-DP methods authored by Professor Victoriano Ramírez González. He noticed that the members of the European Parliament vote erratically. On some occasions they vote on the basis of the ideology of their political party while on other occasions they vote on the basis of national preferences. Therefore the author argues that the number of seats should reflect both factors. As regards voting on the basis of ideological affinity, the allocation should be proportional to the number of inhabitants. National preferences are best represented by proportionality to the square root of the number of inhabitants, which is connected with their voting power - see inter alia [Barbera, Jackson 2006; Beisbart, Bovens 2007; Moberg 2012]. The family of r-DP methods combines these two cases by the allocation function of the form:

$$
A\left(p_{i}\right)=\frac{751 \cdot r \cdot \sqrt{p_{i}}}{\sum_{i=1}^{n} \sqrt{p_{i}}}+\frac{751 \cdot(1-r) \cdot p_{i}}{\sum_{i=1}^{n} p_{i}}, \text { where } r \in[0,1] .
$$

In order to obtain an integer solution, one takes such a value of $k$ that $\sum_{j=1}^{n}$ median $\left(6,\left[k A\left(p_{i}\right)\right], 96\right)=751$, where $\lceil\cdot\rceil$ denotes upwards rounding. The proposed allocation function is hence a convex linear combination of allocations reflecting the above two cases of representation. The parameter $r$ is called a degree of degressivity of allocation. For instance, $r=0.3$ signifies that 70 per cent of seats are distributed proportionally to the number of population, and the remaining 30 per cent - proportionally to the square root of the number of population. Professor González believes that $r$ should equal 0.5 in the case of allocating seats in the European Parliament for the ninth term. The respective allocation will not deviate too much from the status quo in the 2009-2014 term.

\section{Jagiellonian Compromise}

The proposed voting system in the Council of the European Union is not a new idea; see inter alia [Słomczyński, Życzkowski 2004; Słomczyński, Życzkowski 2010]. It consists in assigning each state the voting weight proportional to the square root of its population. The decision-taking threshold in the Council is determined as the quota of the arithmetical mean of the sum of the coalition's weights and the square root of the total population of the Union, i.e. the decision of the Council is taken if the sum of the weights of members of the coalition supporting it exceeds this threshold. Such a solution means that the voting power of each citizen of the Union is roughly the same. The current "double majority" voting system that is binding in the Council now favors the 
largest and the smallest member states. The mathematicians recommend the adoption of the Jagiellonian Compromise as the solution for the voting system in the Council, along with a new allocation of seats in the European Parliament, "to preserve the overall balance of power in the European Union" [Grimmett et al. 2017]. The Jagiellonian Compromise will strengthen the voting power of the medium-sized states. As the proposed systems of allocating seats in the European Parliament will increase the number of representatives of the largest states (except Germany), the simultaneous increase of the voting power of medium-sized states in the Council of the European Union will counterbalance these effects to some extent.

Additional analysis contained in [Grimmett et al. 2017] concerns the size of the European Parliament after Brexit. The authors argue that it should be smaller than the current 751 seats. Assuming further enlargements of the Union, this will allow ensuing allocations without any losses of current seats. The United Kingdom, exiting the EU, has 73 seats, therefore the sizes from the interval $[678,751]$ are considered. The optimum size produced by a given method should minimize the number of states losing seats compared to the status quo in the 2009-2014 term. The "base+power" scheme depending on the assumed base and the rounding method leads to the optimal size of the Parliament equal 723 (base $=4$, upwards rounding), while the 0.5-DPL method returns a size to equal 701 seats. In the first case no state loses seats, while under the solution provided by the 0.5 -DPL method the numbers of seats of five states decrease. All the proposed solutions are presented in Table 3.

\section{Conclusions}

Since its beginning, the composition of the European Parliament has been determined in this way, that its members from more peopled states represented greater numbers of inhabitants than members from less peopled states. However, no legal regulations were involved. After the original idea was officially called "degressive proportionality", its formalization was attempted. Although parliamentarians succeeded in agreeing to the definition of the principle after consultations with scientists, no allocation method from among a number of proposed operational schemes was selected. At the time of writing this paper, members of the European Parliament did not express yet their opinion as regards the allocation solutions proposed for the 2019-2024 term. The consultations conducted in 2017 may be final and conclude many years of striving. 
Table 3. Proposed allocation of seats in the EP in 2019-2024

\begin{tabular}{|c|c|c|c|c|c|}
\hline Country & $p_{i}$ & $\begin{array}{l}\text { base+power } \\
\text { (with UK) }\end{array}$ & $\begin{array}{l}\text { base+power } \\
\text { (without UK) }\end{array}$ & $\begin{array}{c}0.5-\mathrm{DPL} \\
\text { (with UK) }\end{array}$ & $\begin{array}{c}0.5-\mathrm{DPL} \\
\text { (without UK) }\end{array}$ \\
\hline Malta & 434403 & 6 & 6 & 6 & 6 \\
\hline Luxembourg & 576249 & 6 & 6 & 6 & 6 \\
\hline Cyprus & 848319 & 7 & 7 & 6 & 6 \\
\hline Estonia & 1315944 & 7 & 8 & 6 & 6 \\
\hline Latvia & 1968957 & 8 & 9 & 7 & 7 \\
\hline Slovenia & 2064188 & 8 & 9 & 7 & 7 \\
\hline Lithuania & 2888558 & 10 & 11 & 9 & 9 \\
\hline Croatia & 4190669 & 11 & 13 & 11 & 11 \\
\hline Ireland & 4664156 & 12 & 13 & 12 & 12 \\
\hline Slovakia & 5407910 & 13 & 14 & 13 & 13 \\
\hline Finland & 5465408 & 13 & 15 & 13 & 14 \\
\hline Denmark & 5700917 & 13 & 15 & 13 & 14 \\
\hline Bulgaria & 7153784 & 15 & 17 & 16 & 16 \\
\hline Austria & 8711500 & 17 & 19 & 18 & 18 \\
\hline Hungary & 9830485 & 18 & 21 & 19 & 20 \\
\hline Sweden & 9998000 & 18 & 21 & 19 & 20 \\
\hline Portugal & 10341330 & 19 & 21 & 20 & 21 \\
\hline Czech Rep. & 10445783 & 19 & 22 & 20 & 21 \\
\hline Greece & 10793526 & 19 & 22 & 20 & 21 \\
\hline Belgium & 11289853 & 20 & 23 & 21 & 22 \\
\hline Netherlands & 17235349 & 27 & 30 & 28 & 29 \\
\hline Romania & 19759968 & 29 & 33 & 31 & 32 \\
\hline Poland & 37967209 & 49 & 53 & 50 & 53 \\
\hline Spain & 46438422 & 59 & 62 & 59 & 62 \\
\hline Italy & 61302519 & 74 & 76 & 73 & 77 \\
\hline Great Britain & 65341183 & 78 & - & 77 & - \\
\hline France & 66661621 & 80 & 81 & 78 & 82 \\
\hline Germany & 82064489 & 96 & 96 & 93 & 96 \\
\hline TOTAL & 510860699 & 751 & 723 & 751 & 701 \\
\hline
\end{tabular}

Source: [Grimmett et al. 2017]. 


\section{Bibliography}

Barbera S., Jackson M.O. (2006). On the Weights of Nations: Assigning Voting Weights in a Heterogenous Union. Journal of Political Economy 114(2), pp. 317-339.

Beisbart C., Bovens L. (2007). Welfarist Evaluations of Decision Rules for Boards of Representatives. Social Choice and Welfare 29, pp. 581-608.

Cegiełka K. (2010). Distribution of seats in the European Parliament in accordance with the principle of degressive proportionality. Mathematical Economics 6(13), pp. 21-32.

Cegiełka K. (2012). Composition of the European Parliament in 2014-2019 term. Didactics of Mathematics 9(13), pp. 25-34.

Cegiełka K., Dniestrzański P., Łyko J., Misztal A. (2010a). Division of seats in the European Parliament. Journal for Perspectives of Economic Political and Social Integration 26(1-2), pp. 39-59.

Cegiełka K., Dniestrzański P., Łyko J., Misztal A. (2010b). Skład Parlamentu Europejskiego w kontekście podziałów proporcjonalnych. In: A. Barczak (ed.). Badania ekonometryczne w teorii i praktyce. Prace Naukowe Uniwersytetu Ekonomicznego. Katowice, pp. 159170.

Grimmett G.R. (2012). European apportionment via the Cambridge Compromise. Mathematical Social Sciences 63 (2), pp. 68-73.

Grimmett G.R., Pukelsheim F., Ramirez-Gonzalez V., Słomczyński W., Życzkowski K. (2017). The Composition of The European Parliament. Workshop 30 January 2017: compilation of briefings, published by Policy Department for Citizens' Rights and Constitutional Affairs, [http://www.europarl.europa.eu/RegData/etudes/IDAN/2017/583117/ IPOL_IDA(2017)583117_EN.pdf].

Gualtieri R., Trzaskowski R. (2013). Report on the composition of the European Parliament with $a$ view to the 2014 elections. A7-0041/2013.

Lamassoure A., Severin A. (2007). Report on the composition of the European Parliament. A6-0351/2007.

Łyko J., Rudek R. (2013). A fast exact algorithm for the allocation of sets for the EU Parliament. Expert Systems with Applications 40, pp. 5284-5291.

Martinez-Aroza J., Ramirez-Gonzalez V. (2008). Several methods for degressively proportional allotments. A case study. Mathematical and Computer Modelling 48, pp. 14391445.

Moberg A. (2012). EP seats: the politics behind the math. Mathematical Social Sciences 63, pp. 78-84.

Pukelsheim F. (2014). Proportional Representation. Apportionment Methods and Their Applications. Springer.

Ramirez-Gonzalez V. (2007). Degressive proportionality. Composition of the European Parliament. The Parabolic Method. In: Cichocki M., Życzkowski K. (eds.). Institutional Design and Voting Power in the European Union. Ashgate. London, pp. 215-234.

Serafini P. (2011). Allocation of the EU Parliament seats via integer linear programming and revised quotas. Mathematical Social Sciences 63(2), pp. 107-113.

Słomczyński W., Życzkowski K. (2004). Voting in the European Union: The Square Root System of Penrose and a Critical Point. Preprint cond-mat.0405396. 
Słomczyński W., Życzkowski K. (2010). Jagiellonian Compromise - an alternative voting system for the Council of the European Union. In: Cichocki M., Życzkowski K. (eds.). Institutional Design and Voting Power in the European Union. Ashgate. London, pp. 43-57.

Słomczyński W., Życzkowski K. (2012). Mathematical aspects of degressive proportionality. Mathematical Social Sciences 63(2), pp. 94-101.

Treaty of Lisbon (2007). Official Journal of the European Union. C 306. Vol. 50.

Young H.P. (1994). Equity: In theory and practice. Princeton University Press. Princeton. 